\title{
PREDIKSI TINGKAT PELANGGAN CHURN PADA PERUSAHAAN TELEKOMUNIKASI DENGAN ALGORITMA ADABOOST
}

\author{
Iqbal Muhammad Latief ${ }^{1}$, Agus Subekti ${ }^{2}$, Windu Gata ${ }^{3}$ \\ ${ }^{123}$ Prodi Ilmu Komputer, Sekolah Tinggi Ilmu Manajemen dan Ilmu Komputer Nusa Mandiri \\ Jl. Jatiwaringin No. 2, Cipinang Melayu, Makasar Jakarta Timur \\ Telp. (021) 8005722 \\ e-mail : ${ }^{1} 14002323 @$ nusamandiri.ac.id, ${ }^{2}$ agus@ nusamandiri.ac.id, ${ }^{3}$ windu@ nusamandiri.ac.id
}

\begin{abstract}
With the rapid advancement of the telecommunications industry, and competition between telecommunications companies is increasing, companies need to predict their customers to determine the level of customer loyalty. One of them is by analyzing customer data by doing a Customer Churn Prediction. Predicting Customer Churn is an important business strategy for the company. To acquire new customers is much higher cost than retaining existing customers. The ease of operator switching is one of the serious challenges that the telecommunications industry must face. By predicting customer churn, companies can take immediate action to retain customers. To retain existing customers, the company must improve customer service, improve product quality, and must know in advance which customers have the possibility to leave the company. Prediction can be done by analyzing customer data using data mining techniques. In line with this, gathering information from the telecommunications business can help predict whether customer relationships will leave the company. The data used in this study are secondary data and amount to 7.403 data customers. The data has 21 variables. This study proposes to use the ensemble method namely adaboost, xgboost and random forest and compare them. Algorithm is validated through training data and testing data with a ratio of 80:20. From the results we got using python tools, it was found that the adaboost algorithm has an accuracy of $80 \%$.
\end{abstract}

Keywords - accuracy, adaboost, churn prediction, compare model, data mining.

\begin{abstract}
ABSTRAK
Dengan pesatnya kemajuan industri telekomunikasi, dan persaingan antar perusahaan telekomunikasi semakin meningkat, perusahaan perlu untuk memprediksi pelanggannya untuk mengetahui tingkat loyalitas pelanggan. Salah satunya adalah dengan menganalisis data pelanggan dengan melakukan prediksi churn pelanggan. Prediksi churn pelanggan adalah strategi bisnis yang penting bagi perusahaan. Untuk mendapatkan pelanggan baru membutuhkan biaya yang jauh lebih tinggi daripada mempertahankan pelanggan yang sudah ada. Kemudahan operator switching merupakan salah satu tantangan serius yang harus dihadapi oleh industri telekomunikasi. Dengan memprediksi pelanggan churn, perusahaan dapat secara efektif mengambil keputusan untuk mempertahankannya. Untuk mempertahankan pelanggan yang ada, perusahaan harus meningkatkan layanan pelanggan, meningkatkan kualitas produk, dan harus mengetahui sebelumnya pelanggan mana yang memiliki kemungkinan untuk keluar dari perusahaan. Prediksi dapat dilakukan dengan menganalisis data pelanggan menggunakan teknik data mining. Sejalan dengan ini, dengan
\end{abstract}


mengumpulkan informasi dari bisnis telekomunikasi dapat membantu memprediksi hubungan pelanggan apakah mereka akan meninggalkan perusahaan. Data yang digunakan dalam penelitian ini adalah data sekunder dan berjumlah 7.403 data pelanggan. Data memiliki 21 variabel. Studi ini mengusulkan untuk menggunakan metode ensemble yaitu adaboost, xgboost dan random forest dan membandingkannya. Algoritma divalidasi melalui data training dan data testing dengan rasio 80:20. Dari hasil yang kami dapatkan dengan menggunakan alat bantu python maka ditemukan algoritma adaboost memiliki akurasi tertinggi yaitu $80 \%$.

Kata Kunci-adaboost, akurasi, data mining, komparasi model, prediksi churn.

\section{Pendahuluan}

Bidang telekomunikasi telah menjadi salah satu bisnis fundamental di negaranegara maju. Seiring dengan itu perusahaan baru mulai bermunculan. Munculnya perusahaan baru ini mengakibatkan persaingan yang semakin ketat. Perusahaan mana pun dapat berkembang jika memiliki jumlah pelanggan yang memadai. Memiliki jumlah pelanggan yang besar memungkinkan pendapatan yang optimal untuk kas perusahaan. Berbagai cara akan dilakukan perusahaan untuk menarik pelanggan tersebut agar menggunakan jasanya. Salah satu cara untuk menarik pelanggan adalah dengan menganalisis data pelanggan yang biasanya disimpan di sejumlah besar database perusahaan. Data ini dapat digunakan untuk menganalisis pelanggan mana yang loyal dan churn.

Penelitian tentang churn pelanggan semakin penting dan menarik banyak perhatian peneliti [1]. Pelanggan dapat dengan mudah menggunakan haknya untuk berpindah penyedia layanan dari satu operator ke operator lainnya. Banyaknya operator seluler mendorong persaingan bisnis yang semakin ketat. Kemudahan operator switching merupakan salah satu tantangan serius yang harus dihadapi oleh industri telekomuniksi [2]. Mengingat fakta bahwa industri telekomunikasi mengalami tingkat churn tahunan rata-rata 30-35 persen, dan biaya untuk merekrut pelanggan baru 5-10 kali lebih mahal daripada mempertahankan pelanggan yang sudah ada, mempertahankan pelanggan menjadi lebih penting daripada mendapatkan pelanggan [3]. Churn pelanggan mengacu pada kehilangan pelanggan berkala dalam sebuah organisasi [4].

Industri telekomunikasi berusaha mengembangkan cara untuk memprediksi pelanggan yang berpotensi churn sehingga dapat dilakukan tindakan pencegahan karena pengaruh direct churn terhadap penurunan pendapatan perusahaan [5]. Aktivitas churn sangat berpengaruh terhadap total profit dan citra bisnis, 
sehingga sebaiknya dapat diprediksi dan dicegah [6]. Prediksi churn dapat digunakan untuk mengidentifikasi churnes lebih awal sebelum mereka pindah, dan dapat membantu departemen CRM (Customer Relationship Management) untuk mempertahankannya, sehingga potensi kerugian perusahaan dapat dihindari [7]. Dengan demikian penyedia layanan harus mengoptimalkan kinerja model prediksi churn dan menerapkan teknik prediksi churn serta menerapkan strategi pemasaran yang tepat untuk mempertahankan pelanggan yang ada [8].

Masalah yang dihadapi adalah bagaimana menganalisis pelanggan mana yang loyal atau churn. Dalam studi yang dilakukan oleh Keramati disebutkan bahwa untuk bertahan dalam bisnis telekomunikasi harus mampu membedakan antara pelanggan yang memiliki kemungkinan pindah ke pesaing, dan pelanggan yang enggan pindah [9] Oleh karena itu, prediksi churn pelanggan menjadi isu penting dalam bisnis telekomunikasi. Dalam bisnis yang kompetitif, prediktor pelanggan yang andal dianggap sangat berharga.

Proses menghasilkan informasi dari kumpulan data disebut data mining. Contoh penelitian yang telah dilakukan dengan churn analysis adalah pada perusahaan televisi berlangganan [10], perusahaan retail [11], dan lain-lain. Diantara metode data mining yang telah digunakan untuk menganalisis pelanggan adalah random forest dan decision tree [12] tetapi belum mencapai nilai yang sangat baik. Pada penelitian kali ini akan mencoba untuk mendapatkan akurasi yang lebih baik dari penelitian yang dilakukan sebelumnya yang berjudul Telecom Customer Churn Prediction dengan hasil akurasi tertinggi dengan algoritma random forest [12].

Dalam penelitian ini menerapkan teknik klasifikasi data mining yang meliputi random forest, adaboost dan xgboost, kemudian membandingkan performanya.

Pada penelitian ini akan mencoba menjawab bagaimana pengklasifikasian data yang paling berpengaruh terhadap tingkat churn pada perusahaan telekomunikasi menggunakan metode ensemble yaitu random forest, adaboost dan xgboost serta bagaimana akurasi dari ketiga algoritma tersebut.

\section{Metode Penelitian}

Dalam penelitian ini prosedur kerja penelitian ini adalah sebagai berikut:

\section{A) Pemilihan Data}

Dataset dalam penelitian ini adalah data sekunder. Dataset tersebut berisi data pelanggan di sebuah perusahaan 
telekomunikasi. Dataset ini diunduh dari Kaggle dengan alamat website yaitu https://www.kaggle.com/blastchar/telcocustomer-churn. Dataset yang digunakan berukuran 955 KB. Dataset ini memiliki 7.403 data pelanggan dan 21 kolom. 21 kolom tersebut adalah variabel yang akan digunakan sebagai prediksi churn. Variabel yang terdapat dalam dataset churn adalah sebagai berikut [13]:

A. Customer ID: Indeks pelanggan

B. Gender: Jenis kelamin pelanggan. Kolom ini memiliki 2 nilai: male dan female.

C. SeniorCitizen: Pelanggan adalah warga negara senior. Kolom ini memiliki 2 nilai yaitu 0 dan 1 .

D. Partners: Pelanggan memiliki mitra. Kolom ini memiliki 2 nilai, yaitu: Yes dan No.

E. Depedents: Pelanggan memiliki tanggungan. Kolom ini memiliki 2 nilai, yaitu: Yes dan No.

F. Tenure: Jumlah bulan pelanggan menggunakan layanan perusahaan.

G. PhoneService: Pelanggan memiliki layanan telepon. Kolom ini memiliki 2 nilai, yaitu Yes dan No.

H. MultipleLines: Pelanggan memiliki layanan multi saluran. Kolom ini memiliki 2 nilai yaitu Yes dan No.

I. InternetService: Penyedia layanan internet pelanggan. Kolom ini mempunyai 3 nilai yaitu DSL, Fiber Optic dan No.

J. OnlineSecurity: Pelanggan memiliki keamanan online. Kolom ini memiliki 3 nilai yaitu Yes, No dan No Internet Service.

K. OnlineBackup: Pelanggan memiliki layanan tampilan online. Kolom ini memiliki 3 nilai yaitu Yes, No dan No Internet Service.

L. Device Protection: Pelanggan memiliki layanan perlindungan perangkat. Kolom ini memiliki 3 nilai yaitu Yes, No dan No Internet Service.

M. TechSupport: Pelanggan memiliki dukungan teknis. Kolom ini memiliki 3 nilai yaitu Yes, No dan No Internet Service.

N. StreamingTV: Pelanggan memiliki layanan streaming televisi. Kolom ini memiliki 3 nilai yaitu Yes, No dan No Internet Service.

O. StreamingMovies: Pelanggan memiliki layanan streaming film. Kolom ini memiliki 3 nilai yaitu Yes, No dan $N o$ Internet Service.

P. Contract: Persyaratan kontrak pelanggan. Kolom ini memiliki 3 nilai yaitu: Month-to-month, One year, Two year.

Q. PaperlessBilling: Pelanggan memiliki tagihan tanpa kertas. Kolom ini memiliki 2 nilai yaitu: Yes dan No. 
R. PaymentMethod: Metode pembayaran pelanggan. Kolom ini memiliki 4 nilai yaitu: Electronic check, Mailed check, Bank transfer (automatic) dan Credit card (automatic).

S. MonthlyCharges: Ini adalah jumlah yang dibebankan kepada pelanggan setiap bulan.

T. TotalCharges: Jumlah total layanan yang dibebankan kepada pelanggan.

U. Churn: Kategori pelanggan churn atau tidak. Kolom ini memiliki 2 nilai yaitu Yes dan No.

\section{B) Preprocessing}

Setelah data terkumpul, proses selanjutnya adalah proses preprocessing. Preprocessing data merupakan proses yang bertujuan untuk mengubah data menjadi format yang lebih mudah dan efektif bagi pengguna. Beberapa metode preprocessing data yang kami gunakan adalah [14]:

A. Pembersihan data, adalah proses pembersihan data yang memiliki missing value.

B. Penyesuaian data, adalah proses menyesuaikan jumlah data untuk setiap target.

C. Pemisahan data, merupakan proses pemisahan data menjadi dua kelompok yaitu train dan test.

\section{C) Transformation}

Transformation adalah proses mengubah data yang dipilih, sehingga data tersebut sesuai untuk proses data mining. Proses ini merupakan proses kreatif dan sangat bergantung pada jenis atau pola informasi yang akan dicari dalam database. Dalam proses ini, data akan dikelompokkan menggunakan metode One Hot Encoding.

\section{D) Data mining}

Data mining adalah proses mencari pola atau informasi yang menarik dalam data yang dipilih menggunakan teknik atau metode tertentu [15]. Teknik, metode, atau algoritma di dalam data mining itu banyak sekali variasinya. Penelitian ini menggunakan algoritma random forest, adaboost dan xgboost.

\begin{abstract}
Algoritma Adaboost
Adaboost adalah salah satu algoritma boosting yang paling populer. Mirip dengan bagging, ide utama dibalik algoritma adalah membuat sejumlah weak learners yang tidak berkolerasi dan kemudian menggabungkan prediksinya. Perbedaan utama dengan bagging adalah bahwa alih-alih membuat sejumlah rangkaian-rangkaian bootsrap independen, algoritma tersebut secara berurutan melatih setiap weak learner, menetapkan bobot ke semua instance, dan mengulangi
\end{abstract}


seluruh proses. Sebagai algoritma base learner, biasanya decision tree yang terdiri dari satu node digunakan. Decision tree ini, dengan kedalaman satu tingkat, disebut decision stumps.

Algoritma adaboost dapat dideskripsikan secara high-level dari langkah dasarnya, langkah-langkahnya:

1) Inisialisasi semua bobot instance set train secara merata, sehingga jumlahnya sama dengan 1 .

2) Hasilkan set baru dengan pangambilan sampel dengan penggantian, sesuai dengan bobotnya.

3) Train sebuah weak learner pada set sampel.

4) Hitung error pada train set asli.

5) Tambahkan weak learner ke ensemble dan simpan tingkat kesalahannya.

6) Sesuaikan bobot, tambah bobot instance yang salah diklasifikasikan, dan kurangi bobot instance yang diklasifikasikan dengan benar.

7) Ulangi dari langkah 2.

8) Weak learners digabungkan dengan voting. Vote setiap learner diberi bobot sesuai tingkat kesalahannya [16].

Seluruh proses digambarkan dalam gambar berikut:

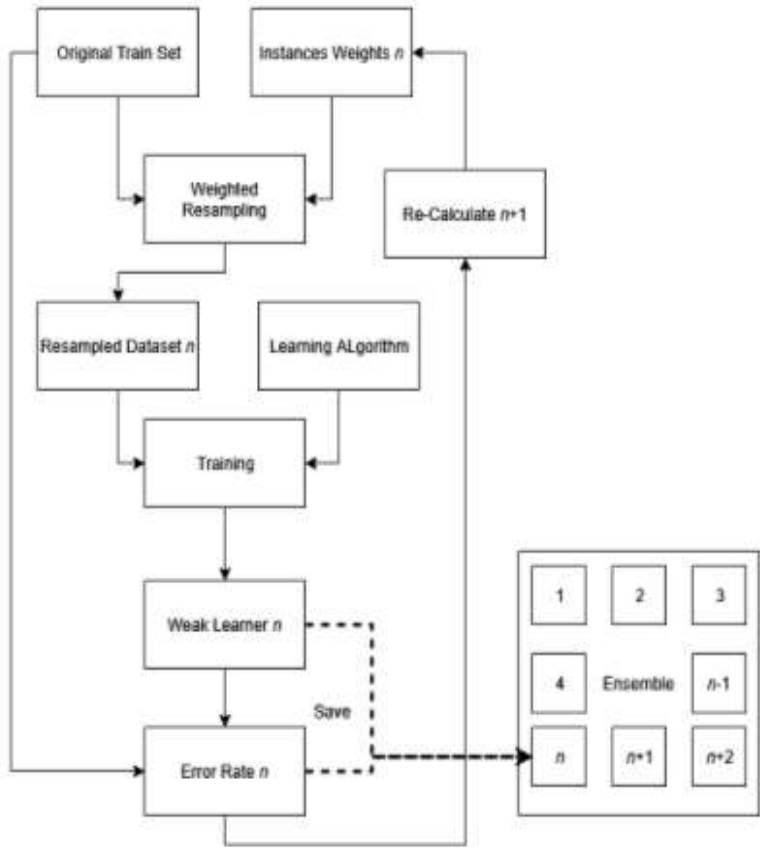

Gambar 1. Langkah-Langkah

Algoritma Adaboost

\section{E) Interpretasi/Evaluasi}

Tahapan mulai dari menyeleksi data yaitu melihat missing value, kemudian melakukan transformasi kebentuk numeric kemudian mencari mendapatkan model terbaik dan terakhir pola informasi yang dihasilkan dari proses data mining perlu ditampilkan dalam bentuk yang mudah dipahami oleh pihak yang berkepentingan. Pada tahap ini, pengetahuan yang dihasilkan dari data mining akan dirilis.

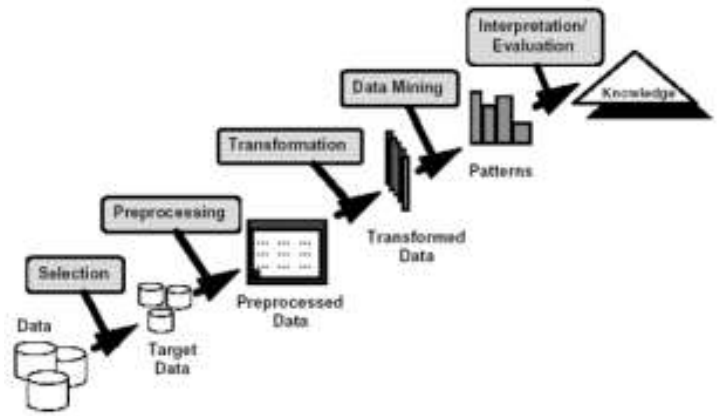

Gambar 2. Proses Data Mining 


\section{HASIL}

Objek yang digunakan dalam penelitian ini adalah data pelanggan pada perusahaan telekomunikasi. Data pelanggan diperoleh dengan mengunduh di Kaggle pada alamat https://www.kaggle.com/blastchar/telcocustomer-churn. Dataset ini berisi 7.043 data pelanggan. Berikut 5 contoh data pelanggan dalam dataset tersebut.

\begin{tabular}{|c|c|c|c|c|c|}
\hline & stomerID & gender & SeniorCitizen & Partner & Dependents \\
\hline 0 & $\begin{array}{r}7590- \\
\text { VHVEG }\end{array}$ & Female & 0 & Yes & No \\
\hline 1 & $\begin{array}{r}5575- \\
\text { GNVDE }\end{array}$ & Male & 0 & No & No \\
\hline 2 & $\begin{array}{r}3668- \\
\text { QPYBK }\end{array}$ & Male & 0 & No & No \\
\hline 3 & $\begin{array}{r}7795- \\
\text { CFOCW }\end{array}$ & Male & 0 & No & No \\
\hline 4 & $\begin{array}{l}9237- \\
\text { HQITU }\end{array}$ & Female & 0 & No & No \\
\hline
\end{tabular}

\section{Gambar 3. Contoh 5 Data Pelanggan} dari Dataset

\begin{tabular}{rrrrr} 
tenure & PhoneService & MultipleLines & InternetService & OnlineSecurity \\
\hline 1 & No & $\begin{array}{r}\text { No phone } \\
\text { service }\end{array}$ & DSL & No \\
34 & Yes & No & DSL & Yes \\
2 & Yes & No & DSL & Yes \\
45 & No & $\begin{array}{r}\text { No phone } \\
\text { service }\end{array}$ & DSL & Yes \\
2 & Yes & No & Fiber optic & No
\end{tabular}

Gambar 4. Lanjutan Contoh 5 Data Pelanggan dari Dataset \begin{tabular}{rlrl} 
DeviceProtection TechSupport & StreaningTV StreamingMovies Contract \\
\hline No & No & No & No Marbs-
\end{tabular} Yes: No No No Oneyear No No No No ManthYes Yes No No Ona your

No No No No Month

\section{Gambar 5. Lanjutan Contoh 5 Data} Pelanggan dari Dataset

\begin{tabular}{|c|c|c|c|c|}
\hline PaperlessBilling & PaymentMethod & MonthlyCharges & TotalCharges & Churn \\
\hline Yes & Electronic check & 2985 & 29.85 & No \\
\hline $\mathrm{No}$ & Mailed check & 56.95 & 1889.5 & No \\
\hline Yes & Mailed check & 53.5 & 108.15 & Yes \\
\hline No & $\begin{array}{r}\text { Bank transfer } \\
\text { (audomatic) }\end{array}$ & 4230 & 1840.75 & No \\
\hline Yes & Electronic check & 7070 & 151.65 & Yes \\
\hline
\end{tabular}

\section{Gambar 6. Lanjutan Contoh 5 Data}

\section{Pelanggan dari Dataset}

Pertama menemukan missing values dari data, kemudian mengisi nya dengan 0 (nol). Terdapat 11 data missing values pada variabel TotalCharges.

Sasaran pada penelitian ini adalah kolom Churn. Jumlah data untuk target "No" adalah 73,4\% dan "Yes" adalah $26,6 \%$.

Sebelum membentuk aturan klasifikasi, perlu dilakukan pembagian data menjadi 2 kelompok yaitu train dan test. Berbagi data ini bertujuan untuk menganalisis apakah aturan klasifikasi yang dihasilkan oleh algoritma adaboost dapat digunakan untuk memprediksi 
churn. Distribusi dataset ini menggunakan rasio $80 \%$ data training dan $20 \%$ data testing .

Kemudian setelah itu dilakukan pemodelan dengan algoritma random forest, adaboost dan xgboost dengan parameter default.

Setalah pemodelan kemudian dilakukan penghitungan akurasi dari masing-masing algoritma, maka didapat hasil seperti gambar 7 .

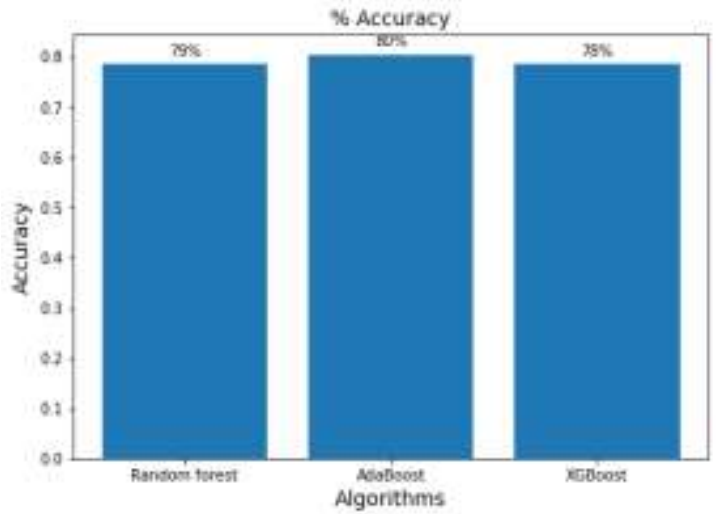

Gambar 7. Perbandingan Ketiga

Algoritma

Dari gambar 7 dapat dilihat bahwa adaboost memiliki akurasi tertinggi yaiu $80 \%$.

Dari Algoritma adaboost, Total Charges, tenure, MonthlyCharges, adalah variabel prediktor paling penting untuk memprediksi Churn.

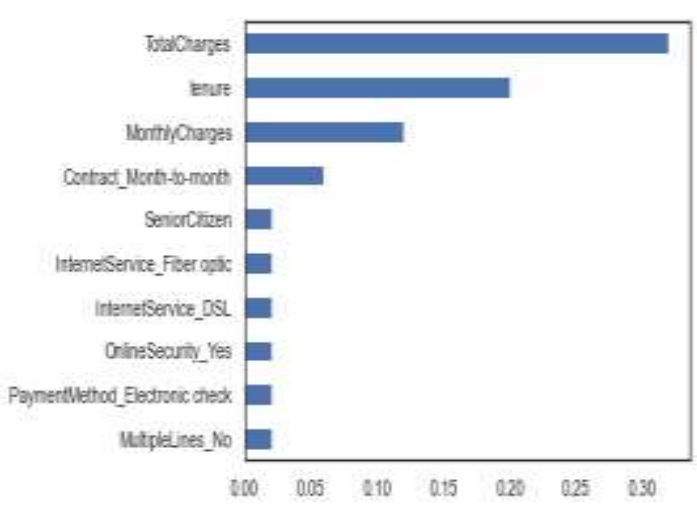

Gambar 8. Variabel Penting yang

\section{Mempengaruhi Churn dengan}

\section{Algoritma Adaboost}

Akurasi yang dihasilkan dari pengujian aturan klasifikasi ini dari data pengujiannya adalah $80 \%$.

Dari aturan klasifikasi yang dibentuk menggunakan algoritma adaboost, variabel TotalCharges memiliki pengaruh cukup kuat terhadap prediksi churn ini.

Dengan mengetahui bahwa variabel TotalCharges memiliki pengaruh yang cukup besar dalam memprediksi churn, maka perusahaan dapat melakukan promosi yang lebih baik kepada pelanggan dengan adanya TotalCharges yang berpotensi churn.

\section{KESIMPULAN}

Setelah melakukan penelitian ini, dapat ditarik kesimpulan bahwa algoritma adaboost dapat memprediksi masalah churn lebih baik dari algoritma random forest dan xgboost serta TotalCharges adalah fitur yang paling penting dalam 
memprediksi churn dengan tingkat akurasi 80\% dari pada penelitian sebelumnya dengan algoritma random forest [12].

\section{DAFTAR PUSTAKA}

[1] E. B. Lee, J. Kim, and S. G. Lee, "Predicting customer churn in mobile industry using data mining technology," Ind. Manag. Data Syst., vol. 117, pp. 90-109, 2017, doi: 10.1108/IMDS-12-2015-0509.

[2] B. Huang, M. T. Kechadi, and B. Buckley, "Customer churn prediction in telecommunications," Expert Syst. Appl., vol. 39, 2012, doi: 10.1016/j.eswa.2011.08.024.

[3] J. Lu and D. Ph, "Predicting Customer Churn in the Telecommunications Industry An Application of Survival Analysis Modeling Using SAS," Techniques, 2002.

[4] A. Churi, M. Divekar, S. Dashpute, and P. Kamble, "Analysis of customer churn in mobile industry using data mining.," Int. J. Emerg. Technol. Adv. Eng., vol. 5(3), pp. 225-230, 2015.

[5] A. K. Ahmad, A. Jafar, and K. Aljoumaa, "Customer churn prediction in telecom using machine learning in big data platform," $J$. Big Data, 2019, doi: 10.1186/s40537-019-0191-6.

[6] J. Pamina, T. Dhiliphan Rajkumar, S. Kiruthika, T. Suganya, and F. Femila, "Exploring hybrid and ensemble models for customer churn prediction in telecom sector,' Int. J. Recent Technol. Eng., 2019, doi: 10.35940/ijrte.A9170.078219.

[7] V. Umayaparvathi and K. Iyakutti, "Applications of Data Mining Techniques in Telecom Churn Prediction," Int. J. Comput. Appl., 2012, doi: 10.5120/5814-8122.

[8] R. Misra, S. Singh, and R. Mahajan, "An empirical study on the cellular subscribers churn, selection factors and satisfaction with the services," 2019, doi:

10.1504/ijpd.2019.10020377.

[9] A. Keramati, R. Jafari-Marandi, M. Aliannejadi, I. Ahmadian, M.

Mozaffari, and U. Abbasi, "Improved churn prediction in telecommunication industry using data mining techniques," Appl. Soft Comput. J., 2014, doi: 10.1016/j.asoc.2014.08.041.

[10] N. Suryana, "PREDIKSI CHURN DAN SEGMENTASI PELANGGAN TV BERLANGGANAN (STUDI KASUS TRANSVISION JAWA BARAT)," J. TEDC, vol. 11(2), no. 
Vol 11 No 2 (2017): Jurnal TEDC,

pp. 185-191, 2019, [Online].

Available:

http://ejournal.poltektedc.ac.id/inde x.php/tedc/article/view/77.

[11] N. W. Wardani, G. R. Dantes, and G. Indrawan, "Prediksi Customer Churn dengan Algoritma Decision Tree C4.5 Berdasarkan Segmentasi Pelanggan untuk Mempertahankan Pelanggan pada Perusahaan Retail," J. Resist. (Rekayasa Sist.

Komputer), 2018, doi:

10.31598/jurnalresistor.v1i1.219.

[12] M. Manasa, M. N. Reddy, M. L. Sahithi, P. Y. Kumar, and V. Sandhya, "Telecom Customer Churn Prediction," vol. 8, 2020, doi: 10.22214/ijraset.2020.5479.

[13] Kaggle, "Telco Customer Churn: Focused customer retention programs," 2018.

https://www.kaggle.com/blastchar/t elco-customer-churn (accessed Nov. 06, 2020).

[14] R. R. Rerung, "Penerapan Data Mining dengan Memanfaatkan Metode Association Rule untuk Promosi Produk," J. Teknol. Rekayasa, 2018, doi: 10.31544/jtera.v3.i1.2018.89-98.

[15] E. Srikanti, R. F. Yansi, Norvahina, I. Permana, and F. N. Salisah,
"Penerapan Data Mining Untuk Menganalisis Penjualan Barang dengan Menggunakan Metode Apriori pada Supermarket Sejahtera Lhoksumawe," J. Ilm. Rekayasa dan Manaj. Sist. Inf., 2018.

[16] G. Kyriakides, Hands-On Ensemble Learning with Python: Build Highly Optimized Ensemble Machine Learning Models Using ScikitLearn and Keras. Birmingham: Packt Publishing Ltd., 2019.

[17] Sabita, H., \& Herwanto, R. (2020).

Pantauan Prediktif Covid-19 Dengan Menggunakan Metode SIR dan Model Statistik Di Indonesia. TEKNIKA, 14(2), 145150. 